\title{
Comparative tomographic study of the S2-alar-iliac screw versus the iliac screw
}

\author{
Mauro Costa Morais Tavares Junior ${ }^{1}$. João Paço Vaz de Souza ${ }^{1} \cdot$ Thiego Pedro Freitas Araujo $^{2}$. \\ Raphael Martus Marcon ${ }^{1}$. Alexandre Fogaça Cristante ${ }^{1} \cdot$ Tarcísio Eloy Pessoa de Barros Filho $^{1}$. Olavo Biraghi Letaif ${ }^{1}$
}

Received: 25 March 2018 / Accepted: 24 October 2018 / Published online: 31 October 2018

(c) The Author(s) 2018

\begin{abstract}
Aims Iliac screws and S2-alar-iliac screws provide adequate mechanical stability for the fixation of lumbosacral spine pathologies, which has led to a significant increase in the use of these techniques in the routine practice of spine surgeons. However, studies on the ideal technical positioning for both techniques are limited.

Study design This is an observational, retrospective, analytical descriptive study.

Objective To analyze, describe and compare the insertion and positioning parameters of the S2-alar-iliac and iliac screw techniques in adult patients without spinal deformities.

Methods The present study comprises a retrospective analysis of lumbosacral computed tomography images selected continuously in 2016 from 25 patients at a university hospital. Mann-Whitney-Shapiro-Wilk tests were performed. Data reliability was assessed using intraclass correlation.

Results The mean length of the iliac screw was greater than that of the S2-alar-iliac screw, and the S2-alar-iliac screw sat $20.5 \mathrm{~mm}$ deeper than the iliac screw. The mean of the greatest bone thickness for the iliac screw was $20.72 \mathrm{~mm}$; that of the S2-alar-iliac screw was $23.24 \mathrm{~mm}$. The mean distance from the iliac screw entry point to the skin was $32.46 \mathrm{~mm}$, and the mean distance from the S2-alar-iliac screw entry point to the skin was $52.87 \mathrm{~mm}$.

Conclusion The trajectory of the S2-alar-iliac screws studied via computed tomography was greater in terms of bone thickness and deeper relative to the skin compared with the iliac screws. The S2-alar-iliac technique may have desirable clinical advantages in terms of the diameter of the screws and reduced protrusion when used in adults.
\end{abstract}

Graphical abstract These slides can be retrieved from Electronic supplementary material.


Keywords S2AI $\cdot$ Iliac screw $\cdot$ Tomographic $\cdot$ Radiology $\cdot$ Anatomy $\cdot$ Lumbosacral

Electronic supplementary material The online version of this article (https://doi.org/10.1007/s00586-018-5806-7) contains supplementary material, which is available to authorized users.

Extended author information available on the last page of the article

\section{Introduction}

Spinopelvic rigid fixation is often necessary for the treatment of complex spinal pathologies [1]. The options described in the literature refer to the Galveston technique, developed by 
Allen BL, Jr., and Ferguson RL, which involves the longitudinal insertion of a bar between the two cortices of the iliac bone, or to more modern techniques, such as the use of the iliac screw (IS) and the S2-alar-iliac screw (S2AI) [2-4].

Lumbosacral arthrodesis may present mechanical complications that can lead to insufficient or decreased bone consolidation. The use of screws in the iliac bone reduces the incidence of these complications compared with the Galveston technique. However, the use of iliac screws may also present problems, the most common of which are screw prominence and surgical wound infection [5-7]. The S2AI fixation technique, originally described by Kebaish and Sponseller, reduces the incidence of these problems due to minimal dissection of soft tissues and an insertion point that is far from the skin, which facilitates the construction of the system since the entry point is aligned with the lumbar and S1 pedicular screws $[8,9]$.

Both the IS and the S2AI provide mechanical stability for the fixation of lumbosacral spine pathologies, which has led to a significant increase in the use of these techniques in the routine practice of spine surgeons. However, studies on the ideal technical positioning of both techniques are limited [10-12]. In addition, no reports have categorically determined the best positioning of the implant or performed a comparison between these techniques [1-3].

The present study aims to analyze, describe and compare the insertion and positioning parameters of the S2AI and IS techniques in adult patients without spinal deformities using computed tomography (CT).

\section{Methods}

The present study comprises a retrospective analysis of lumbosacral CT images, selected continuously in 2016, from 25 patients who underwent elective procedures at a university hospital to investigate abdominal-pelvic pathologies (nephrolithiasis and diverticular disease). CT images and measurements were collected and analyzed using ISite ${ }^{\circledR}$ Enterprise software (Philips, Amsterdam, The Netherlands). Thin-section images with bone window were used for the measurements.

Inclusion criteria are lumbosacral CT images containing axial, sagittal and coronal sections with the possibility of reconstruction in three dimensions (3D); age between 18 and 65 years; and absence of bone fracture or tumor in the lumbosacral spine. Exclusion criteria are inappropriate images; age extremes; incomplete records; skeletally immature patients; and vertebrae with congenital bone malformation or fusion defects.

Data were stored in an Excel ${ }^{\circledR}$ for Mac spreadsheet (Microsoft Corporation, Redmond, Wash.). After input conferencing, the data were imported into SPSS ${ }^{\circledR} 23$ for Mac
(IBM, Armonk, New York) for statistical analysis. Continuous data were described by the mean and its respective standard deviation (SD) and 95\% confidence interval (95\% $\mathrm{CI}$ ), and categorical data were described by the absolute frequency and the respective categorical proportion. Inferential statistics were performed to compare between sides and between different locations relative to the tomography measurements. The data were tested for adherence to a normal distribution, and since no normal distribution was observed, a nonparametric paired comparison test, the Mann-Whitney-Shapiro-Wilk test, was performed. Intraclass correlation was performed to assess data reliability. A type I error of up to $5 \%$ was accepted as a statistically significant difference. Statistical analyses were performed by an independent statistician blinded to the data.

\section{Methodology of data analysis}

The measurements were obtained independently by four examiners (two orthopedic residents and two spine surgery fellows) with various levels of experience. The examiners were trained to perform measurements prior to the study, and ten cases were selected solely for training purposes. These cases were not included in the final sample. The same training set was used for all measurement evaluations, and the acceptable threshold variation was $2^{\circ}-3^{\circ}$ or $2-3 \mathrm{~mm}$. The measures were standardized as follows: age was measured in years; sex as male or female; thickness, length and width were measured in millimeters; and angle was measured in degrees.

Standardization of IS measurements:

- Length: measured through the insertion point of the IS (posterior-superior iliac crest) to the anterior-inferior iliac crest;

- Sagittal angle: tilt angle of the IS in the sagittal section of CT;

- Axial angle: angle of inclination of the IS in the axial section of CT;

- Maximum thickness: the greatest thickness between the external cortices of the iliac crest;

- Minimum thickness: the smallest thickness between the external cortices of the iliac crest in its isthmic region; and

- Skin distance: the distance between the insertion point of the IS and the skin.

Standardization of S2AI measurements:

- Length: perpendicular distance between the insertion point of the S2AI (between the foramen of S1 and S2, 
$2 \mathrm{~mm}$ lateral to the paramedian sacral crest up to the anterior-inferior iliac crest);

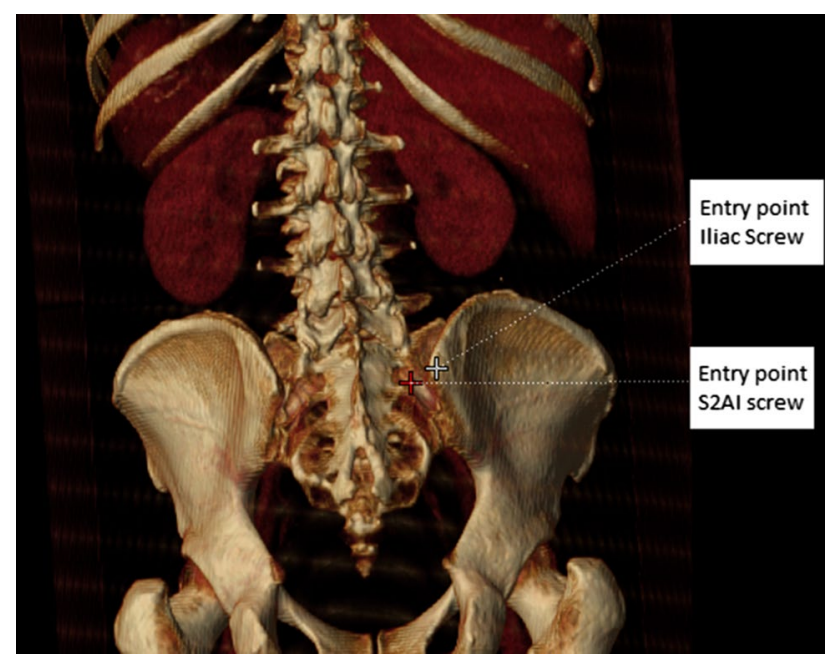

Fig. 1 Example of the entry points for the S2-alar-iliac screw (shown by the red cross) and the iliac screw (shown by the white cross)
- Sagittal angle: tilt angle of the S2AI in the sagittal section of CT;

- Axial angle: angle of the inclination of the S2AI in the axial section of CT;

- Maximum thickness: the greatest thickness between the external cortices of the iliac crest;

- Minimum thickness: the smallest thickness between the external cortices of the iliac crest in its isthmic region; and

- Skin distance: perpendicular distance between the insertion point of the S2AI and the skin.

Examples of measurements are shown in Figs. 1,2 and 3.

\section{Results}

In this study, 25 pelvic CT images were analyzed, including 12 from males and 13 from females. The mean age was 48.7 years $( \pm 11.7 \mathrm{SD})$. Reliability analysis indicated that screw length and axial angle were highly reliable.
Fig. 2 Example of the S2AI screw length (between the two white crosses)

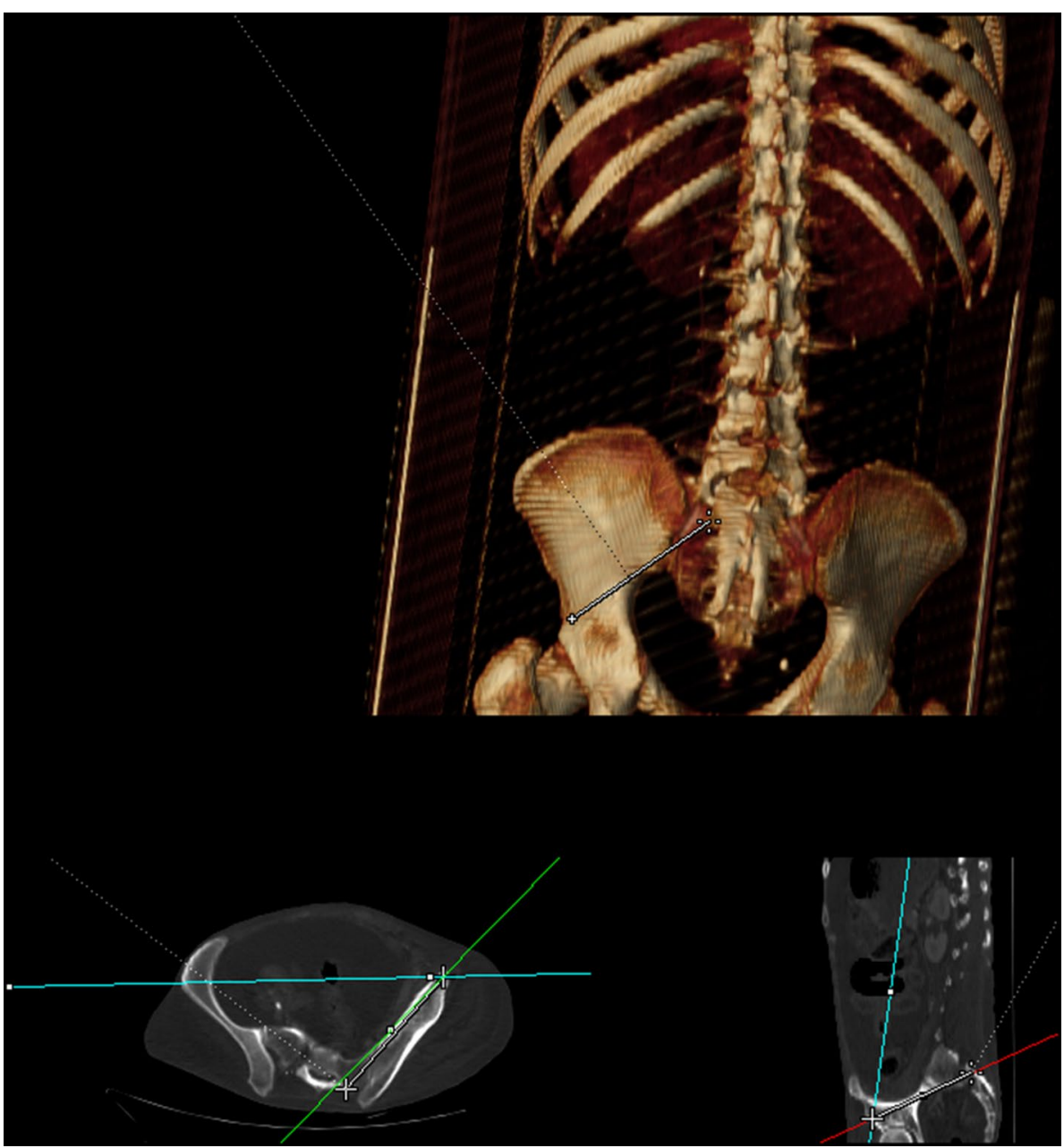


Fig. 3 Example of the iliac screw length (between the two white crosses)

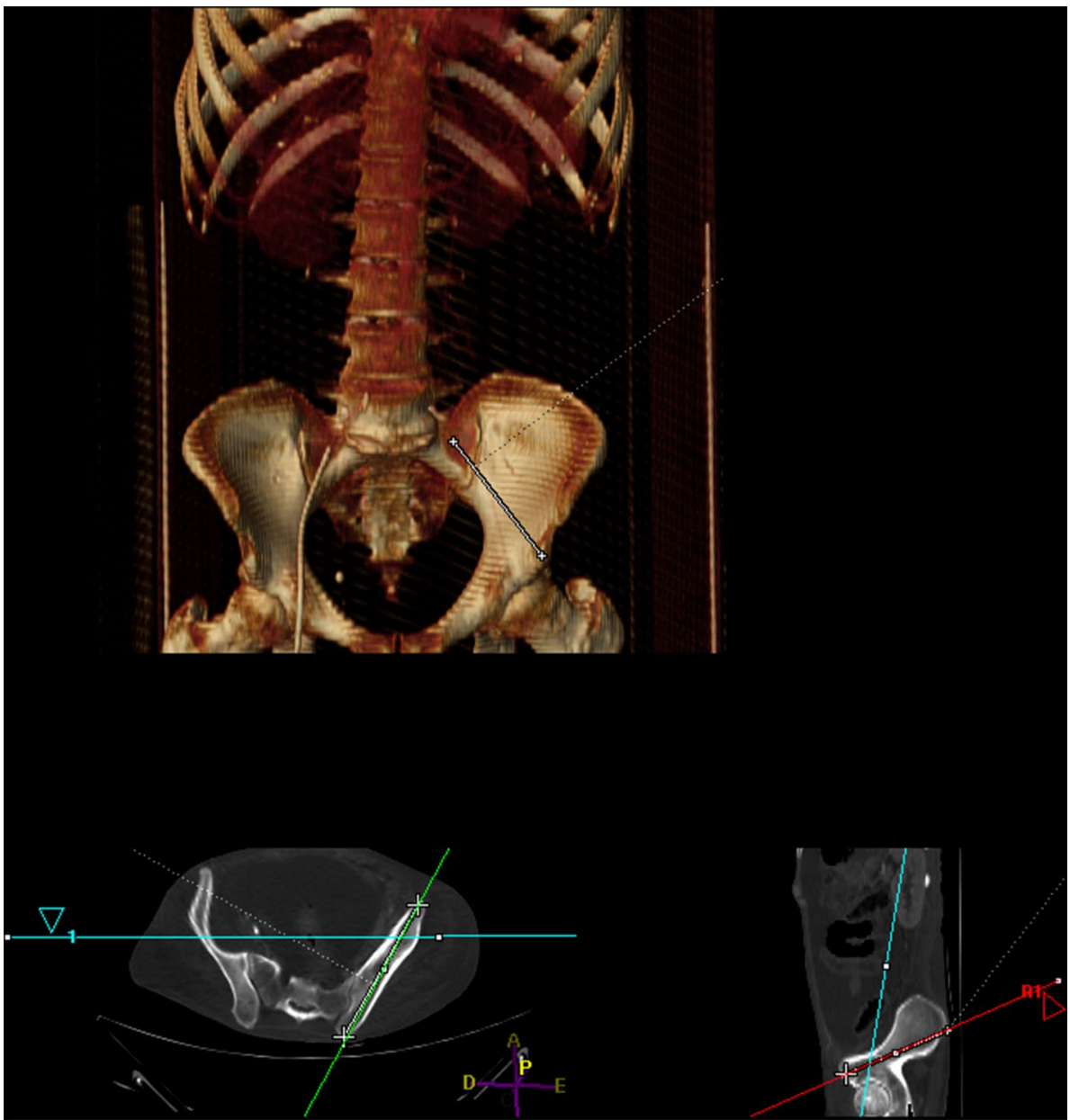

The mean length of the IS was $141.53 \mathrm{~mm}( \pm 8.40 \mathrm{SD})$. The mean length of the S2AI was $133.67 \mathrm{~mm}( \pm 9.89$ $\mathrm{SD})$. The mean of the maximum bone thickness of the IS was $20.72 \mathrm{~mm}( \pm 2.54 \mathrm{SD})$, and that of the S2AI was $23.24 \mathrm{~mm}( \pm 2.27 \mathrm{SD})$. The mean of the minimum bone thickness of the IS was $15.94 \mathrm{~mm}( \pm 2.34 \mathrm{SD})$, and that of the S2AI was $17.94 \mathrm{~mm}( \pm 2.23 \mathrm{SD})$.

The mean axial angle at the point of entry of the IS was $22.56^{\circ}( \pm 2.08 \mathrm{SD})$ and that of the S2AI was $33.91^{\circ}$ $( \pm 2.20 \mathrm{SD})$. The mean sagittal angle of the IS entry point was $26.68^{\circ}( \pm 2.87 \mathrm{SD})$, and that of the S2AI was $29.92^{\circ}( \pm 2.33 \mathrm{DP})$. The mean distance from the skin to the IS entry point was $32.46 \mathrm{~mm}( \pm 15.02 \mathrm{SD})$, and the mean distance from the skin to the S2AI entry point was $52.87 \mathrm{~mm}( \pm 18.34 \mathrm{SD})$.

Statistically significant differences were obtained for all variables analyzed, as shown in Table 1 .

The reliability of the examiners' measurements is summarized in Tables 2 and 3.

\section{Discussion}

The present study demonstrated by pelvic CT that the entry point angles, skin distances, thicknesses and lengths differed for the placement of the IS and the S2AI in adult patients. Regarding the screw trajectory, that of the IS was $7.8 \mathrm{~mm}$ longer than that of the S2AI on average, and the greatest bone thickness of the iliac crest was $2.4 \mathrm{~mm}$ larger for the S2AI than for the IS. This study also showed that the S2AI sat $20.5 \mathrm{~mm}$ deeper than the IS. These data (length, thickness and skin distance) showed statistically significant differences between the two screw trajectories.

Chang et al. [13] reported results similar to those described above in 20 adolescents aged $12-18$ years in a population in the USA. The mean angulation values of the axial and sagittal S2AI in that study were $39^{\circ}$ and $38^{\circ}$, respectively. In the present study, the angulation values were $33.9^{\circ}$ and $29.9^{\circ}$. Regarding the IS in the same study, 
Table 1 Mann-Whitney-Shapiro-Wilk test

\begin{tabular}{|c|c|c|c|c|c|}
\hline Data & Mean difference & $\begin{array}{l}\text { Standard } \\
\text { deviation }\end{array}$ & $\begin{array}{l}95 \% \text { confidence inter- } \\
\text { val }(\mathrm{CI}) \text { - superior }\end{array}$ & $\begin{array}{l}95 \% \text { confidence inter- } \\
\text { val }(\mathrm{CI}) \text { - inferior }\end{array}$ & $p$ value \\
\hline Screw length: iliac versus S2AI & 7.861 & 5.701 & 6.241 & 9.481 & $<0.01$ \\
\hline Maximum bone thickness: iliac versus S2AI & -2.524 & 2.026 & -3.100 & -1.948 & $<0.01$ \\
\hline Minimum bone thickness: iliac versus S2AI & -1.999 & 1.789 & -2.507 & -1.490 & $<0.01$ \\
\hline Axial screw angle: iliac versus S2AI & -11.355 & 1.935 & -11.905 & -10.805 & $<0.01$ \\
\hline Sagittal screw angle: iliac versus S2AI & -3.234 & 2.641 & -3.985 & -2.483 & $<0.01$ \\
\hline Distance from skin: iliac versus S2AI & -20.412 & 7.113 & -22.433 & -18.391 & $<0.01$ \\
\hline
\end{tabular}

Table 2 Intraclass correlation coefficient-overall

\begin{tabular}{llll}
\hline Data & $\begin{array}{l}\text { Intraclass cor- } \\
\text { relation* }\end{array}$ & $\begin{array}{l}95 \% \text { confidence interval } \\
(\mathrm{CI}) \text {-superior limit }\end{array}$ & $\begin{array}{l}\text { 95\% confidence inter- } \\
\text { val (CI)-inferior limit }\end{array}$ \\
\hline Screw length & $0.815^{\mathrm{a}}$ & 0.760 & 0.862 \\
Maximum bone thickness & $0.532^{\mathrm{a}}$ & 0.316 & 0.687 \\
Minimum bone thickness & $0.455^{\mathrm{a}}$ & 0.248 & 0.618 \\
Axial screw angle & $0.854^{\mathrm{a}}$ & 0.809 & 0.893 \\
Sagittal screw angle & $0.397^{\mathrm{a}}$ & 0.253 & 0.532 \\
Distance from skin & $0.919^{\mathrm{a}}$ & 0.888 & 0.942 \\
\hline
\end{tabular}

*Interpretation: less than $0.400>$ poor; $0.400-0.599$ > fair; $0.600-0.749>$ good; $0.750-1.00>$ excellent

${ }^{a}$ The estimator is the same whether the interaction effect is present or not the mean axial and sagittal angulation values were $21^{\circ}$ and $39^{\circ}$, versus $22^{\circ}$ and $27^{\circ}$ in the present study [13].

According to the literature, the angulation described for the screw trajectory varies considerably and may present a difference of up to $15^{\circ}$ in the sagittal plane [14]. In Chang's work, the trajectory of the IS screws was longer than that of the S2AI screws, but the authors noted that although most surgeons select screws with lengths ranging from 50 to $75 \mathrm{~mm}$, the length of the S2AI screw trajectory still exceeds these values. Importantly, the individuals studied in Chang's work were younger than those selected in the present study, and some individuals with immature skeletons may have been included.

Another important consideration from a surgical and postoperative standpoint is the distance from the screws to the skin. We found distances of $32 \mathrm{~mm}$ for the IS screws and $53 \mathrm{~mm}$ for the S2AI screws. This detail is important for the care of sick, underweight and bedridden patients, which is the reality for many patients with spinal deformities undergoing scoliosis correction surgery. This difference results in greater soft tissue coverage over the screw head and, consequently, a lower risk of exposure. The work by Chang et al. [13] observed a similar difference to that found in our study. In the Chang study, the difference was on average $15 \mathrm{~mm}$ deeper in favor of the S2AI screw.

Despite the concordance among some of the data published in this work with the literature, some numerical differences exist. Such variations in measured values can be explained by the choice of different entry points described in the studies, since even millimeter differences can alter the final measured result [3]. Deviations in lumbopelvic patterns according to race, ethnicity, sex, skeletal maturity and age may explain the differences in the measurements and may lead to changes in the angulation of the insertion of the screws and in their trajectories [15-18].

Most studies have focused on American populations, though some also describe Chinese, Malay and Indian populations [13, 19, 20]. However, no studies describe these data in Brazilian populations or even in Latin American groups. Such descriptions in different populations are important to improve our understanding of individual spinal anatomy and morphology.

The present study followed a retrospective design, which may lead to bias in the sample selection. Regardless, because objective and numerical parameters were measured, the retrospective nature of the present study is a minor limitation. Another possible criticism is the lack of a comprehensive population with a large age range yet already skeletally mature. Age can ultimately act as a confounding factor, especially if there is potential for bone growth. The mean age in our study was 48.7 years $( \pm 11.7 \mathrm{SD})$, an age group that is expected to present regular radiological parameters. Another consideration is the data collection by evaluators with differing levels of experience. More senior and experienced evaluators may have greater expertise in performing the measurements, given their increased familiarity with 
Table 3 Intraclass correlation coefficient-comparative

\begin{tabular}{|c|c|c|c|}
\hline Data & $\begin{array}{l}\text { Intraclass correla- } \\
\text { tion }\end{array}$ & $\begin{array}{l}95 \% \text { confidence interval } \\
\text { (CI)—superior limit }\end{array}$ & $\begin{array}{l}\text { 95\% confidence inter- } \\
\text { val (CI)—inferior limit }\end{array}$ \\
\hline \multicolumn{4}{|l|}{ Screw length } \\
\hline \multicolumn{4}{|l|}{ Iliac } \\
\hline Single measures & $0.920^{\mathrm{a}}$ & 0.880 & 0.949 \\
\hline Average measures & $0.979^{\mathrm{b}}$ & 0.967 & 0.987 \\
\hline \multicolumn{4}{|l|}{ S2AI } \\
\hline Single Measures & $0.715^{\mathrm{a}}$ & 0.606 & 0.810 \\
\hline Average measures & $0.909^{\mathrm{b}}$ & 0.860 & 0.944 \\
\hline \multicolumn{4}{|c|}{ Maximum bone thickness } \\
\hline \multicolumn{4}{|l|}{ Iliac } \\
\hline Single measures & $0.526^{\mathrm{a}}$ & 0.258 & 0.715 \\
\hline Average measures & $0.816^{\mathrm{b}}$ & 0.582 & 0.909 \\
\hline \multicolumn{4}{|l|}{ S2AI } \\
\hline Single measures & $0.403^{\mathrm{a}}$ & 0.207 & 0.584 \\
\hline Average measures & $0.730^{\mathrm{b}}$ & 0.511 & 0.849 \\
\hline \multicolumn{4}{|c|}{ Minimum bone thickness } \\
\hline \multicolumn{4}{|l|}{ Iliac } \\
\hline Single measures & $0.395^{\mathrm{a}}$ & 0.148 & 0.606 \\
\hline Average measures & $0.723^{\mathrm{b}}$ & 0.410 & 0.860 \\
\hline \multicolumn{4}{|l|}{ S2AI } \\
\hline Single measures & $0.416^{\mathrm{a}}$ & 0.226 & 0.593 \\
\hline Average measures & $0.740^{\mathrm{b}}$ & 0.539 & 0.853 \\
\hline \multicolumn{4}{|l|}{ Axial screw angle } \\
\hline \multicolumn{4}{|l|}{ Iliac } \\
\hline Single measures & $0.396^{\mathrm{a}}$ & 0.252 & 0.550 \\
\hline Average measures & $0.724^{\mathrm{b}}$ & 0.575 & 0.830 \\
\hline \multicolumn{4}{|l|}{ S2AI } \\
\hline Single measures & $0.422^{\mathrm{a}}$ & 0.279 & 0.573 \\
\hline Average measures & $0.745^{\mathrm{b}}$ & 0.607 & 0.843 \\
\hline \multicolumn{4}{|l|}{ Sagittal screw angle } \\
\hline \multicolumn{4}{|l|}{ Iliac } \\
\hline Single measures & $0.489^{\mathrm{a}}$ & 0.335 & 0.638 \\
\hline Average measures & $0.793^{\mathrm{b}}$ & 0.669 & 0.876 \\
\hline \multicolumn{4}{|l|}{ S2AI } \\
\hline Single measures & $0.214^{\mathrm{a}}$ & 0.075 & 0.379 \\
\hline Average measures & $0.522^{\mathrm{b}}$ & 0.244 & 0.710 \\
\hline \multicolumn{4}{|l|}{ Distance from skin } \\
\hline \multicolumn{4}{|l|}{ Iliac } \\
\hline Single measures & $0.903^{\mathrm{a}}$ & 0.856 & 0.939 \\
\hline Average measures & $0.974^{\mathrm{b}}$ & 0.960 & 0.984 \\
\hline \multicolumn{4}{|l|}{ S2AI } \\
\hline Single measures & $0.884^{\mathrm{a}}$ & 0.810 & 0.931 \\
\hline Average measures & $0.968^{\mathrm{b}}$ & 0.944 & 0.982 \\
\hline
\end{tabular}

${ }^{a}$ The estimator is the same whether the interaction effect is present or not

${ }^{\mathrm{b}}$ This estimate is calculated considering that the interaction effect is absent because it can not be estimated otherwise these trajectories. We aimed to control this bias by standardizing the measurements through previous training of all the evaluators as well as the senior researcher in this study.
The measurement parameters and technique are reproducible and consistent, as shown by the high intra- and interobserver reliability. More experienced examiners obtained 
slightly more reliable measurements. The standardization of the measurements was effective and homogeneous. Discrete differences in measurements $\left(2^{\circ}-3^{\circ}\right.$ or 3 - to $4-\mathrm{mm}$ differences in the means) are not typically clinically significant and reflect only a numerical and merely statistical difference. Among the overall measurements, the length of the IS, axial angle and skin distance exhibited a high degree of reliability (Tables 2, 3).

No significant differences were observed with respect to sex or laterality. Therefore, for greater representability, the right and left laterality data were analyzed as a single group.

Although that was not the focus of this present study, another important aspect regarding the employment of the $\mathrm{S} 2 \mathrm{AI}$ technique is the possible modification in the relations of the spinopelvic measures caused by the implant position in the lumbopelvic region. It is said that pelvic incidence is a constant morphological parameter after skeletal maturity; however, several recent studies have questioned these data $[21,22]$. This fact deserves future research, including 3D analysis.

To the best of our knowledge, this work represents the first study to perform a comparative and integrated analysis of different parameters of the insertion trajectory of IS and S2AI screws in an adult population with the aid of CT for models with $3 \mathrm{D}$ reconstruction. These findings are fundamental and timely since the use of spinopelvic fixation is becoming increasingly common. Studies with larger or multicentric population samples may expand and consolidate the information collected in the present study, including clinical trials.

\section{Conclusion}

The trajectory of S2AI screws studied via CT in an adult population was greater in terms of thickness and deeper relative to the skin compared with IS screws. The S2AI technique, when used in adults, may present desirable clinical advantages related to the diameter of the chosen screws and reduced protrusion.

\section{Compliance with ethical standards}

Conflict of interest The authors declare that there are no conflicts of interest related to the present study.

Open Access This article is distributed under the terms of the Creative Commons Attribution 4.0 International License (http://creativeco mmons.org/licenses/by/4.0/), which permits unrestricted use, distribution, and reproduction in any medium, provided you give appropriate credit to the original author(s) and the source, provide a link to the Creative Commons license, and indicate if changes were made.

\section{References}

1. Santos ERG, Sembrano JN, Mueller B, Polly DW (2011) Optimizing iliac screw fixation: a biomechanical study on screw length, trajectory, and diameter. J Neurosurg Spine 14:219-225

2. Mattei TA, Fassett DR (2013) Combined S-1 and S-2 sacral alar-iliac screws as a salvage technique for pelvic fixation after pseudarthrosis and lumbosacropelvic instability: technical note. J Neurosurg Spine 19:321-330

3. Liu B, Wang J, Zhang L, Gan W (2014) Radiographic study of iliac screw passages. J Orthop Surg Res 9:40

4. Park SA, Kwak DS, You SL (2015) Entry zone of iliac screw fixation to maintain proper entry width and screw length. Eur Spine J 24:2573-2579

5. Zhu F, Bao HD, Yuan S, Wang B, Qiao J, Zhu ZZ, Liu Z, Ding YT, Qiu Y (2013) Posterior second sacral alar iliac screw insertion: anatomic study in a Chinese population. Eur Spine J 22:1683-1689

6. O'Brien JR, Yu W, Kaufman BE, Bucklen B, Salloum K, Khalil S, Gudipally M (2013) Biomechanical evaluation of S2 alar-iliac screws: effect of length and quad-cortical purchase as compared with iliac fixation. Spine (Phila Pa 1976) 38:E1250-E1255

7. OBrien JR, Warren DY, Bhatnagar R, Sponseller P, Kebaish KM (2009) An anatomic study of the S2 iliac technique for lumbopelvic screw placement. Spine (Phila Pa 1976) 34:E439-E442

8. Sponseller P (2007) The S2 portal to the ilium. Semin Spine Surg 2:8387

9. O'Brien JR, Matteini L, Yu WD, Kebaish KM (2010) Feasibility of minimally invasive sacropelvic fixation: percutaneous $\mathrm{S} 2$ alar iliac fixation. Spine 35:460-464

10. Mazur MD, Ravindra VM, Schmidt MH, Brodke DS, Lawrence BD, Riva-Cambrin J, Dailey AT (2015) Unplanned reoperation after lumbopelvic fixation with S-2 alar-iliac screws or iliac bolts. J Neurosurg Spine 23:67-76

11. Matteini LE, Kebaish KM, Volk WR, Bergin PF, Yu WD, O'Brien JR (2010) An S-2 alar iliac pelvic fixation. Technical note. Neurosurg Focus 28:E13

12. Ray WZ, Ravindra VM, Schmidt MH, Dailey AT (2013) Stereotactic navigation with the O-arm for placement of S-2 alar iliac screws in pelvic lumbar fixation. J Neurosurg Spine 18:490-495

13. Chang TL, Sponseller PD, Kebaish KM, Fishman EK (2009) Low profile pelvic fixation. Spine 34:436-440

14. Nottmeier EW, Pirris SM, Balseiro S, Fenton D (2010) Threedimensional image-guided placement of S2 alar screws to adjunct or salvage lumbosacral fixation. Spine J 10:595-601

15. Gardner MJ, Routt MLC Jr (2011) Transiliac-transsacral screws for posterior pelvic stabilization. J Orthop Trauma 25:378-384

16. Garrido BJ, Wood KE (2011) Navigated placement of iliac bolts: description of a new technique. Spine J 11:331-335

17. Dalbayrak S, Yilmaz M, Kaner T, Gokdag M, Yilmaz T, Sasani M, Oktenoglu T, Ozer AF (2011) Lumbosacral stabilization using iliac wings: a new surgical technique. Spine (Phila Pa 1976) 36:E673-E677

18. Yu BS, Zhuang XM, Li ZM, Zheng ZM, Zhou ZY, Zou XN, Lu WW (2010) Biomechanical effects of the extent of sacrectomy on the stability of lumbo-iliac reconstruction using iliac screw 
techniques: what level of sacrectomy requires the bilateral dual iliac screw technique? Clin Biomech 25:867-872

19. Tian X, Li J, Sheng W, Qu D, Ouyang J, Xu D, Chen S, Ding Z (2010) Morphometry of iliac anchorage for transiliac screws: a cadaver and CT study of the Eastern population. Surg Radiol Anat 32:455-462

20. Zheng ZM, Yu BS, Chen H, Aladin DM, Zhang KB, Zhang JF, Liu H, Luk KD, Lu WW (2009) Effect of iliac screw insertion depth on the stability and strength of lumbo-iliac fixation constructs: an anatomical and biomechanical study. Spine (Phila Pa 1976) 34:E565-E572
21. Cecchinato R, Redaelli A, Martini C, Morselli C, Villafañe JH, Lamatina C, Berjano P (2017) Long fusions to S1 with or without pelvic fixation can induce relevant acute variations in pelvic incidence: a retrospective cohort study of adult spine deformity surgery. Eur Spine J 26(Suppl 4):S436-S441

22. Tseng C, Liu Z, Bao H, Li J, Zhao Z, Hu Z, Qiu Y, Zhu Z (2018) Long fusion to the pelvis with $\mathrm{S} 2$-alar-iliac screws can induce changes in pelvic incidence in adult spinal deformity patients: analysis of predictive factors in a retrospective cohort. Eur Spine J. https://doi.org/10.1007/s00586-018-5738-2

\section{Affiliations}

\section{Mauro Costa Morais Tavares Junior ${ }^{1}$. João Paço Vaz de Souza ${ }^{1}$. Thiego Pedro Freitas Araujo ${ }^{2}$. Raphael Martus Marcon ${ }^{1}$. Alexandre Fogaça Cristante ${ }^{1}$. Tarcísio Eloy Pessoa de Barros Filho ${ }^{1}$. Olavo Biraghi Letaif ${ }^{1}$}

Mauro Costa Morais Tavares Junior mauro_div@ hotmail.com

1 Department of Orthopedics and Traumatology, IOT HCFMUSP, 171 Dr. Ovídio Pires de Campos St., São Paulo, SP 05403010, Brazil
2 Spine Surgery, IOT HCFMUSP, São Paulo, Brazil 